\title{
Possible solutions for oxygenation support in critically ill patients with COVID-19
}

\author{
Daniel Baldoino de Souza ${ }^{1}$ (D) $\cdot$ Adriano de Oliveira Andrade ${ }^{1}$ (D) $\cdot$ Selma Terezinha Milagre ${ }^{1}$ (D) \\ Adriano Alves Pereira ${ }^{1}$
}

Received: 26 May 2020 / Accepted: 22 December 2020 / Published online: 3 January 2021

(C) Sociedade Brasileira de Engenharia Biomedica 2021

\begin{abstract}
Purpose Due to the large number of patients with respiratory deficiency during the COVID-19 pandemic, several governments and their respective health care services have been studying ways to complement the care provided by offering immediate solutions. In view of this, the aim of this study was to carry out a systematic review of the advantages and disadvantages of possible solutions in oxygenation support.

Methods This systematic review used the PRISMA-P methodology and sought to list alternatives in oxygenation support that are being applied and studied worldwide. A bibliographic search was conducted in the MEDLINE and Cochrane Central databases, using the keywords SARS-CoV-2, COVID19, or coronavirus; combined with extracorporeal membrane oxygenation (ECMO), mechanical ventilation, mechanical ventilation support, low-cost, anesthesia, anesthesia machine, and ventilation therapy. The records were also found in the gray literature.

Results The search found 85 publications of which 41 articles were considered after excluding duplicate articles, reading the title and summary, and reading the articles in full. The oxygenation supports identified in these publications were the following: ECMO, shared mechanical ventilator, fast or low-cost production equipment, high-flow nasal cannula (HFNC), non-invasive ventilation, and use of anesthesia equipment as a mechanical ventilator.

Conclusion This study demonstrated the importance of a trained clinical team in the application of technologies. The alternatives found for support oxygenation require a more robust clinical evaluation to demonstrate their efficacy and safety for the COVID-19 patient.
\end{abstract}

Keywords COVID19 $\cdot$ ECMO $\cdot$ Mechanical ventilator $\cdot$ Anesthesia equipment

\section{Introduction}

On 11 March 2020, the World Health Organization (WHO) declared a pandemic state for SARS-COV-2 (severe acute respiratory syndrome-coronavirus), responsible for COVID19 (COrona VIrus Disease), with more than 118,000 confirmed cases of the disease in 110 countries. One of the objectives of this decree was to inform and alert the world about the continuous and rapid dynamics of the disease spread. In addition, there was a need to prepare the health system of

Daniel Baldoino de Souza

danielufu@gmail.com

1 Centre for Innovation and Technology Assessment in Health, Postgraduate Program in Electrical and Biomedical Engineering, Faculty of Electrical Engineering, Federal University of Uberlândia, Uberlândia, Brazil countries to face the likely and imminent significant increase in the demand for health care (Ducharme 2020).

There are reports of the existence and pathogenicity of several types of coronavirus such as respiratory, gastrointestinal, liver and neurological diseases in animals. Coronaviruses were first discovered in poultry in the 1930s. They are enveloped RNA viruses with the presence of protein spikes on their surface. Seven of the coronaviruses identified so far may cause disease in humans $(\mathrm{HCoV})$, four of which cause mild infections (HCoV-NL63, HCoV-229E, HCoV-OC43, HCoV-HKU1) and the other three can cause outbreaks of lethal pneumonia (SARS-CoV, MERS-CoV and SARSCoV2) (Levison 2020).

SARS-CoV emerged in November 2002 in Guangdong province, China, and caused an epidemic that spread across 29 countries, contaminated 8000 people and killed 800 of them (Levison 2020). It originates from a cat-like mammal that is sold on the Guangdong market and, when introduced 
into humans may be transmitted by respiratory droplets, aerosols and by fecal-oral transmission. The MERS-CoV (Middle East respiratory syndrome-coronavirus) appeared at the Arabian Peninsula in September 2012 and had a fatality rate of $35 \%$. Transmission can occur between humans through direct contact, fomites and respiratory droplet (Levison 2020).

As reported by the Pan American Health Organization (PAHO), the SARS-CoV-2 virus was initially identified at Wuhan, Hubei province, China. The infection may have originated in bats, the primary hosts of the virus and its migration to humans appears to have occurred in the market for seafood and live animals, through an intermediate host called pangolin (scaly mammal, anteater). Its transmission between humans occurs through respiratory droplets, through contact with contaminated surfaces, as well as bringing contaminated hands to the eyes, nose or mouth, in addition to possible fecal-oral transmission (Levison 2020; Pan American Health Organization 2020). The most common symptoms of this pathology are fever, tiredness and dry cough, but there may also be more severe symptoms such as high fever, pneumonia and difficulty in breathing (Pan American Health Organization 2020).

Due to this scenario and the agility of modern means of transport, this epidemic has spread to several countries around the world. Other factors that have also contributed to this spread can be attributed to the scarcity of tests to help diagnose this new virus and, also, to the delay in releasing the results of the existing tests, which has contributed to the contamination of doctors, nurses, physiotherapists and other members of the multiprofessional team providing direct assistance to infected patients. In this way, the epidemiological surveillance commissions provided recommendations to assist in the containment of the spread of the spread of the disease. These include the protection of health professionals with personal protective equipment and the rapid identification, testing and isolation of infected individuals, symptomatic or non-symptomatic (Silva 2020; World Health Organization (WHO) 2020a).

As pointed out in Khandaker et al. (2011), about 5\% of H1N1 cases require admission to the Intensive Care Unit (ICU), and 2.3\% require mechanical ventilation. The lethality rate for COVID-19 is estimated to be between 0.5 and $4 \%$ (World Health Organization (WHO) 2020a), which is low compared to 35\% for MERS-CoV (Levison 2020) and approximately similar to that for the Spanish flu, which ranged from 2 to 3\% (World Health Organization (WHO) 2009), with about $80.9 \%$ of the cases disease being mild (Chinese Medical Association 2020). The lethality rate of the SARS-CoV-2 virus, although low, has a high transmissibility power compared, for example, with the MERS-CoV virus where the lethality rate is significantly higher, but the transmissibility rate is lower (Tsouderos 2020), however, the hospitalization rate can be between 15 and $18 \%$ according to National Library of Medicine (2020e).
In this context, ventilatory therapy techniques are essential to increase the chance of survival for infected patients who are among the most serious cases of infection. In these cases, respiratory therapy acts as a compromised physiological function, allowing the patient more time to fight the infection, improving the chances of recovery and restoring the physiological functions performed by his respiratory system (National Library of Medicine 2020c).

The use of a mechanical ventilator is the traditional method of ventilatory therapy. An orotracheal or nasotracheal tube or a tracheostomy cannula is used for invasive ventilation (Carvalho et al. 2007). Several types of therapy, some of which are used in the mechanical ventilation technique, are being evaluated to help patients recover from the advanced stage of severe acute respiratory syndrome. The use of nitric oxide gas, vitamin $C$, streptokinase, or even heparin with fractionated nebulization aids some of these respiratory therapies.

To show the importance of respiratory therapy techniques, clinical staff can use the ordinal scale at the first assessment of the day, during the monitoring of COVID-19 patient. In this scale, items 2,3 , and 4 are related to some type of respiratory therapy. As showed by National Library of Medicine (2020b), we have:

1) Death;

2) Hospitalized, under invasive mechanical ventilation or extracorporeal membrane oxygenation (ECMO);

3) Hospitalized, needing supplemental oxygen;

4) Hospitalized, no need for supplemental oxygen;

5) Not hospitalized, activity limitation;

6) Not hospitalized, without activity limitations.

Nowadays, mechanical ventilators are safe and reliable and are indispensable in medium and high complexity hospital environments. However, they have a high cost of acquisition, in addition to relying on high costly accessories and consumable, such as the medicinal gases, for example (Darwood et al. 2019). Such peculiarities have an impact on the availability of this type of equipment in health care services, the quantity of which is quite limited.

Due to the large number of patients with respiratory deficiency during the COVID-19 pandemic, several governments and their respective health care services have been studying ways to complement the care provided by offering immediate solutions. These measures are not always approved by the health agencies responsible, both for guaranteeing the method used and for monitoring the quality and safety control of health care measures implemented as an urgent solution to the lack of a mechanical ventilator. Given this problem, this study aimed to carry out a systematic review of the advantages and disadvantages of possible solutions in oxygenation support used in respiratory therapies, which are being proposed and used as an alternative to the scarcity of the ventilation 
equipment in various health institutions around the world in the cases of COVID-19.

\section{Methods}

This systematic review used the methodology followed as presented by Moher et al. (2016) called Preferred Reporting Items for Systematic Reviews and MetaAnalysis (PRISMA-P).

\section{Study design}

The protocol defined by the PRISMA-T guidelines was followed. Thus, the entire review process of the articles was carried out by three reviewers and their summary is in the PRISMA flow diagram shown in Fig. 1.

\section{Inclusion/exclusion criteria}

Eligible articles included studies with oxygenation support that were related to severe cases of SRDA, prospective cohort studies, case-control, systematic reviews, meta-analyses, randomized clinical trials, and non-randomized studies associated with COVID-19. The research included all languages and was limited to articles published between January 1, 2007, and April 30, 2020. A bibliographic review was conducted, between March and April 2020. Studies carried out in laboratories and which did not include the analysis of sensitivity were excluded.

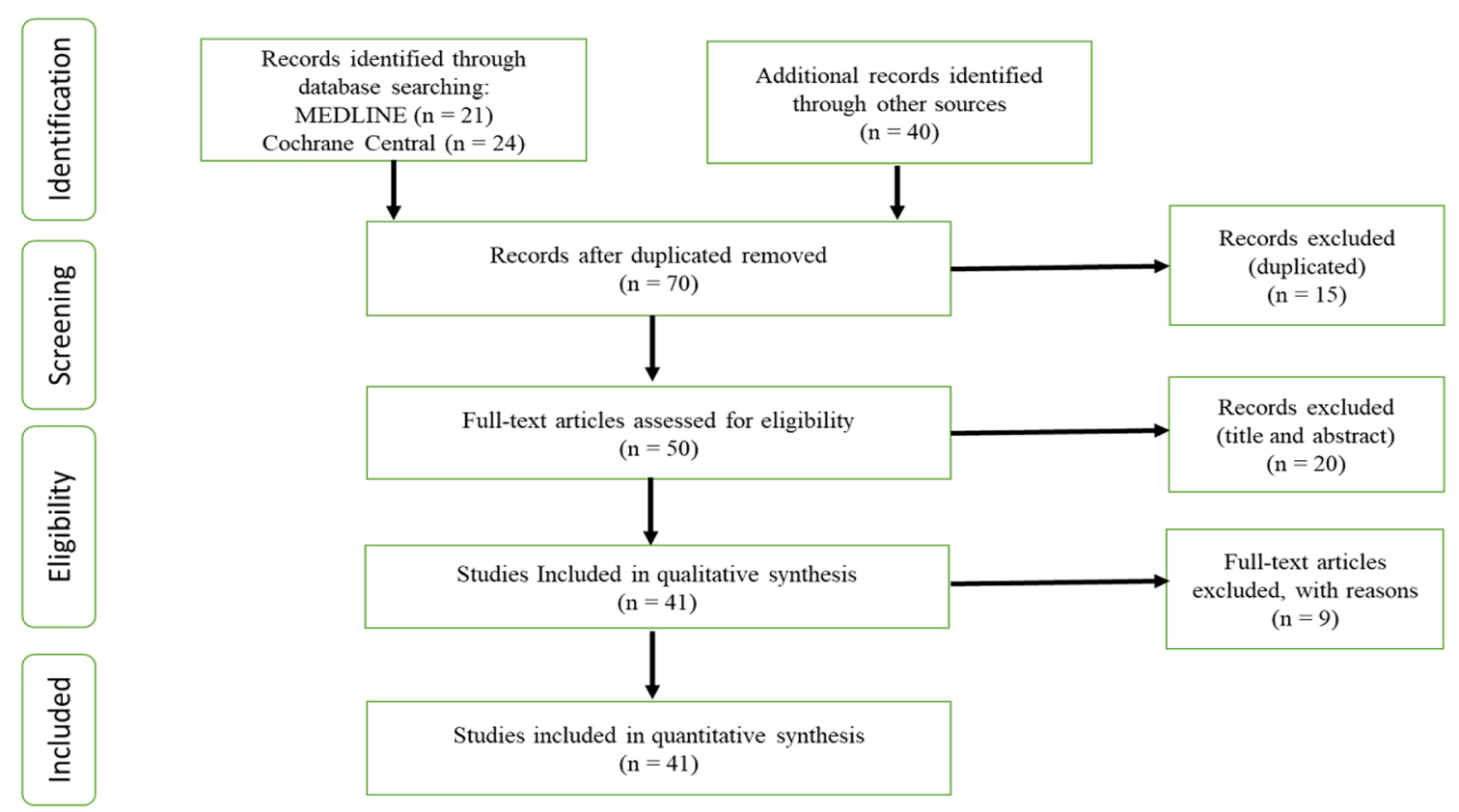

\section{Search sources}

Of the three main worldwide databases for systematic review in the health field (EMBASE, Cochrane Central, and Medline), the Cochrane Central and Medline databases were used, because the EMBASE database is focused only on European results. Google and manual search of bibliographies and summaries of the main articles were used to search for additional information.

Thus, for this study, two databases indicated for COVID19 were used: Cochrane Central and MEDLINE. The following keywords were used to carry out this systematic review: (“SARS-CoV-2” OR “COVID19” OR “coronavírus”) AND ("ECMO” OR "mechanical ventilator" OR "mechanical ventilatory support" OR "low-cost” OR "anesthesia” OR "anesthesia machine" OR "ventilatory therapy"). Two authors analyzed the articles for titles and full abstracts.

The gray literature was searched in government sites, professional associations, and companies. In these cases, the same words used in white literature searches were used as a scope for the research.

\section{Selection}

Two authors (DBS and AAP) independently analyzed the titles and abstracts of all studies identified in the research strategy and discarded those that were duplicated. The studies considered eligible were reassessed by reading their full texts, which make up this systematic review. In cases where a disagreement occurred on the chosen articles, the opinion of the third author was requested. However, no study required

Fig. 1 PRISMA flow diagram 
consultation with a third reviewer. The selection process for this study is shown in Fig. 1.

\section{Data collection}

Two authors (AOA and STM) extracted data from the selected articles, as well as their accuracy and fidelity, and a third author resolved the disagreements that arose throughout the process.

\section{Sensitivity analysis}

Sensitivity analysis was used to ensure that the number of studies was sufficient and relevant, according to the proposal of Higgins and Green (2006), which contains 5 items:

a) "Changing the inclusion criteria for the types of study (e.g., using different methodological cut-points), participants, interventions or outcome measures

b) Including or excluding studies where there is some ambiguity as to whether they meet the inclusion criteria

c) Reanalyzing the data using a reasonable range of results for studies where there may be some uncertainty about the results (e.g., because of inconsistencies in how the results are reported that cannot be resolved by contacting the investigators, or because of differences in how outcomes are defined or measured)

d) Reanalyzing the data inputting a reasonable range of values for missing data

e) Reanalyzing the data using different statistical approaches (e.g., using a random effects model instead of a fixed effect model, or vice versa)".

Due to the current moment, item a was not evaluated, as our inclusion criteria were flexible. Item e was also not evaluated because the objective of this systematic review is not a metaanalysis. Thus, items b, c, and d were analyzed as follows:

- All articles that presented treatment with oxygenation support, but that was not the main focus of the study, were excluded.

- All publications that were related to case reports, case series, abstracts, and expanded abstracts were excluded.

- All articles that caused doubts about the inclusion in this systematic review were re-analyzed for relevance.

- Studies with failure to follow up above $10 \%$ were excluded.

\section{Results}

Based on the adopted methodology, 85 articles have been identified, including 21 articles are from the MEDLINE database, others 24 articles from the Cochrane Central database and 40 publications from the gray literature have been included to complement this subject, which has been widely discussed by scientific and academic circles. Of these articles, 15 presented duplicate themes, remaining 70 . The titles and abstracts of these 70 articles were read, where 20 of these articles were eliminated because they dealt with different subjects, leaving 50 articles. After analysis of the full texts, 41 studies were considered for this systematic review. These studies can be seen in Table 1 .

As shown in the PRISMA (Preferred Reporting Items for Systematic Reviews and Meta-Analyses) flow diagram in Fig. 1, 41 publications found in the MEDLINE, Cochrane Central, and other sources of publication were considered eligible. Various forms of treatment of patients with COVID-19 using different drugs are presented in these articles, but the points of interest in this study were those related to respiratory therapy used in the publications identified.

\section{Discussion}

The COVID-19 pandemic causes concern to health centers in different countries, especially when the infection curve peaks due to its high hospitalization rate (National Library of Medicine 2020e), causing difficulties for local managers take care of a large number of patients dependent on alternative oxygenation support on respiratory therapy, either through ECMO or through mechanical ventilation (National Library of Medicine 2020f, 2020d).

The mortality of patients hospitalized with COVID-19 is very high, as there is still no effective therapeutic modality (Shenoy et al. 2020). However, the Surviving Sepsis Campaign panel recommends that mechanically ventilated patients with COVID-19 should be treated in the same way as other patients with acute respiratory failure in the ICU, despite this recommendation, there are still few studies addressing mechanical ventilation strategies in patients with COVID-19 (Alhazzani et al. 2020).

Knowing the characteristics of individuals with severe SRDA due to COVID-19 is important, but these data are scarce. Based on this verification (Yang et al. 2020) they carried out an observational study with 52 patients with severe COVID-19, admitted to the intensive care unit (ICU) of the Wuhan Jin Yin-tan Hospital (Wuhan, China). The results showed that $71 \%$ of patients required mechanical ventilation and that mechanical ventilation is the main supportive treatment for individuals critically ill with COVID-19.

In according to Wunsch (2020) there is a worldwide surveillance for patients with COVID-19, particularly those who are receiving mechanical ventilation. For the author, there are two key questions regarding ventilation, the first is when to intubate and the second is the reported mortality for patients 
Table 1 List of the studies found

\begin{tabular}{|c|c|}
\hline Analyzed subjects & References \\
\hline ECMO & $\begin{array}{l}\text { Arabi et al. (2017) } \\
\text { Chu et al. (2018) } \\
\text { Colafranceschi et al. (2020) } \\
\text { Combes et al. (2018) } \\
\text { Extracorporeal Life Support Organization (2020a) } \\
\text { Extracorporeal Life Support Organization (2020b) } \\
\text { Guery et al. (2013) } \\
\text { Ramanathan et al. (2020) } \\
\text { Schmidt et al. (2020) }\end{array}$ \\
\hline Mechanical ventilator - splitter & $\begin{array}{l}\text { American Association for Respiratory Care (2020) } \\
\text { American Society of Anesthesiologists (2020b) } \\
\text { Benjamim (2020) } \\
\text { Branson (2006) } \\
\text { Cavanilles et al. (1979) } \\
\text { Guery et al. (2013) } \\
\text { Neyman and Irvin (2006) } \\
\text { Paladino et al. (2008a) } \\
\text { Powner et al. (1977) } \\
\text { Prisma Health (2020) }\end{array}$ \\
\hline $\begin{array}{l}\text { Low cost or fast manufactured } \\
\text { ventilator }\end{array}$ & $\begin{array}{l}\text { Chandler (2020) } \\
\text { Husseini et al. (2010) } \\
\text { Medicines and Healthcare products Regulatory Agency (2020) } \\
\text { Shahid (2019) }\end{array}$ \\
\hline $\begin{array}{l}\text { Anesthesia machines as lung } \\
\text { ventilators }\end{array}$ & $\begin{array}{l}\text { American Society of Anesthesiologists (2020a) } \\
\text { Anesthesia Patient Safety Foundation (2020) } \\
\text { Food and Drug Administration (2020b) } \\
\text { Mindray (2020) }\end{array}$ \\
\hline High-flow nasal cannula & $\begin{array}{l}\text { Guo et al. (2020) } \\
\text { Singhal (2020) } \\
\text { Zhao et al. (2017) }\end{array}$ \\
\hline Non-invasive ventilation & $\begin{array}{l}\text { Medicines and Healthcare products Regulatory Agency (2020) } \\
\text { National Library of Medicine (2020b, 2020e, 2020f, 2018) } \\
\text { Singhal (2020) } \\
\text { Zhao et al. (2017) }\end{array}$ \\
\hline Dilemma (ethics, security, planning) & $\begin{array}{l}\text { Berlinger et al. (2020) } \\
\text { BRASIL (2020) } \\
\text { Food and Drug Administration (2020a) } \\
\text { Hick et al. (2007) } \\
\text { National Library of Medicine (2020a, 2020b, 2020c, 2020d, 2020e, } \\
\text { 2020f, 2018) }\end{array}$ \\
\hline
\end{tabular}

receiving mechanical ventilation. In addition to the issues highlighted by Wunsch, another concern is the risk of mortality in relation to oxygen saturation. Chu et al. (2018) carried out a systematic review with meta-analysis comparing liberal and conservative oxygen therapy; the study involved 25 randomized clinical trials and 16,037 patients; the authors highlight the need to establish upper oxygen limits for supplementation of oxygen to occur safely. The result of the meta-analysis indicated that liberal oxygen therapy increased mortality and that supplemental oxygen may be unfavorable with $\mathrm{SpO}_{2}$ rates above 94-96\%.

The health care services, spread across various countries facing the most critical cases of COVID-19, must address the lack of mechanical ventilators as one of their priorities 
(Chandler 2020). As a result, several governmental or nongovernmental organizations, such as university research laboratories from universities and private companies from different branches, have been prepared to develop technical solutions for ventilatory support therapies.

Some of the solutions proposed by several countries to help make available a larger quantity of equipment are the following: increased workload in factories (with production lines running $24 \mathrm{~h}$ a day); conversion and adaptation of several plants for the production of mechanical ventilators; intense research into low-cost ventilator development projects to specifically serve COVID-19 patients; research and testing on the use of new techniques for sharing the same mechanical ventilation equipment with 2 or more patients; use of anesthesia equipment as mechanical ventilators, and search and use of new procedures about oxygenation support, such as extracorporeal membrane oxygenation (ECMO), always with the aim of maintaining the exchange of gas between patients for as long as possible, allowing the recovery of the patient's organism.

\section{ECMO}

There are still several doubts, divergences, and inconsistencies in the effectiveness and application of oxygenation, within the scope of COVID-19, for patients with severe ARDS (Chu et al. 2018; Schmidt et al. 2020). Regarding ECMO, many results show mortality rates between 84 and $100 \%$ of patients with COVID-19. However, in the retrospective cohort study conducted with 492 patients from the Paris-Sorbonne University Hospital Network, the results indicated similarity with published studies for patients with severe ARDS from other diseases. The authors consider that ECMO should be considered for patients who have developed refractory respiratory failure (Schmidt et al. 2020).

The Extracorporeal Life Support Organization (ELSO) is monitoring the procedures and conducting studies on ECMO worldwide and, as indicated by the National Academy of Medicine of Brazil, this procedure has three indications: cardiac, respiratory, or cardiorespiratory support (Colafranceschi et al. 2020). ECMO contraindications refer to multiple organ dysfunction, pre-existing terminal disease, inability to use anticoagulants, advanced age, generalized infection, and inability to install vascular accesses, among others (Colafranceschi et al. 2020).

This technique works as a gas exchange supportive therapy and does not directly treat the cause that leads the patient to need this support. This procedure can be used as rescue therapy in patients with acute respiratory failure. Its application can be indicated even if the lung is unable to exchange gases with the aid of a ventilator. However, the patient must be hemodynamically stable (Colafranceschi et al. 2020).
During the MERS-CoV epidemic, this technique was used to assist patients' respiratory therapy. However, in many cases, it has been used in patients with multiple organ dysfunction and chronic renal failure. A further detail of its use was the application in conjunction with the mechanical ventilation of patients (Arabi et al. 2017; Guery et al. 2013).

Hemorrhage (10-30\%), neurological complications (4$37 \%$ ), and mechanical circuit complications (19\%) are among the most common complications of ECMO use, with the worst results following cardiac arrest (Combes et al. 2018). Studies have shown that satisfactory results from the use of ECMO are more frequent when associated with severe respiratory distress syndrome requiring pulmonary support without the need of circulatory support.

ELSO recommendations for the use of ECMO in cases of COVID-19 include patients with severe forms of acute respiratory distress syndrome (ARDS) or even those with refractory cardiocirculatory impairment. The initial experience reported by Extracorporeal Life Support Organization (2020a) in patients with COVID-19 in Japan and South Korea has been positive for younger patients with minor or nonexistent comorbidities, but the decision must be approved by the medical staff. Thus, when patients meet these characteristics, the ECMO should be started immediately, avoiding delay in its execution (Extracorporeal Life Support Organization 2020a).

In the ECMO procedure, blood is drained from the venous vascular system and driven by a mechanical pump through an oxygenation membrane, which is subsequently reinfused back into the venous or arterial circulation. In this process, hemoglobin is saturated with oxygen outside the body and carbon dioxide is removed. Considering the high rates of death in patients hospitalized in intensive care units, and transmission through aerosols produced during the breathing process in patients affected by COVID-19, patient preparation for ECMO becomes very relevant (Ramanathan et al. 2020).

The possibility of SARS-CoV-2 crossing the membrane used in ECMO oxygenation is a recent concern that has stimulated discussions among the professionals responsible for the installation and operation of ECMO (Extracorporeal Life Support Organization 2020b). According to current discussions, there are not yet enough studies to confirm or refute the hypothesis that the extracorporeal membrane is permeable to the virus that causes COVID-19. However, it is worth highlighting some relevant observations arising from these discussions on the permeability of the membrane and its possible deterioration. Regarding the permeability of the membrane, the pore diameter of a microporous membrane of the oxygenator is about $0.04-0.10 \mathrm{~nm}$ and the diameter of the SARS-CoV-2 virus is about $0.06-0.14 \mathrm{~nm}$. A certain similarity is observed in the diameters of the virus and the microporous membrane but the virus is slightly larger than the ECMO membrane. In addition, there is difference in charge and potential between the fabrication material and its surface coating, 
which can prevent the virus from crossing the membrane. In this sense, it seems likely that the risk of SARS-CoV-2 crossing the membrane and potentially spreading the disease is lower than when compared to the spread of the respiratory tract through endotracheal intubation and mechanical ventilation (Extracorporeal Life Support Organization 2020b).

The membrane may deteriorate with the prolonged use of ECMO and, in some cases, as in the microporous membrane, the oxygenator fibers may rupture, resulting in possible plasma leakage through the exhalation pathway. In this case, the pores of the membrane are enlarged and the surface loses its character of charge and potential and is capable of generating an aerosol containing SARS-CoV-2 (Extracorporeal Life Support Organization 2020b).

Reports of experience in patients with positive sputum for COVID-19 PCR in the covered ECMO membrane and for 10 days without plasma leakage showed negative results for PCR in the exhalation pathway samples. However, positive results were obtained in the exhalation route in the case of plasma leakage reports in hospitals in Japan. Strict control of the proper operating conditions of the oxygenator must therefore be maintained, avoiding the reduction of its exchange threshold before starting the deterioration process (Extracorporeal Life Support Organization 2020b).

Another relevant study that deserves attention was developed by Combes et al. (2018) in which patients with severe acute respiratory syndrome (SARS) were randomly assigned to two groups. One group was treated with ECMO and the other by conventional ventilation. The primary endpoint was mortality at 60 days. Thus, it was observed that the mortality rate of patients with SARS was not significantly lower in ECMO-treated patients compared to conventional-treated patients, despite a higher number of hemorrhagic events in ECMO-treated patients.

The studies presented here show that greater success in the use of this type of therapeutic procedure is satisfactory, preferably when applied to younger patients with an indication only for therapeutic support of acute respiratory syndrome, without compromising the cardiovascular system, hemodynamically stable and without any other type of comorbidity. Therefore, in the case of patients affected by COVID-19, strict monitoring of the operating conditions of the oxygenator must be maintained in order to prevent the deterioration of its membrane with probable plasma leakage and possible dissemination of SARS-Cov-2 via the ECMO system exhalation pathway (Colafranceschi et al. 2020; Combes et al. 2018; Extracorporeal Life Support Organization 2020a, b; Ramanathan et al. 2020).

\section{Mechanical ventilator-splitter}

Another solution that is being widely discussed and studied is the sharing of respiratory devices with two or more patients, to be used as an extreme emergency measure by some health services, as an alternative to alleviating the critical situation of scarcity of these devices. This procedure has been used to respond to the growing number of patients presenting the most severe form of clinical manifestations of COVID-19 in these services. It should be noted that, in parallel with this situation, several research centers have sought to develop protocols and are conducting tests to implement this technique safely.

There have been reports since 1977 of the possibility of using the same ventilator performing differential ventilation of the lungs of the same patient (Powner et al. 1977). The study presented by Powner et al. (1977) shows that when small changes are made to the patient's circuit, the right and left sides of the lung of a single patient can be ventilated independently. For example, this procedure can be used to treat unilateral pneumonia. This method enables the control of the differentiated PEEP and the separation of the exhaled gas.

The benefits of respiratory therapy for a single patient per mechanical ventilator are positive, as it provides the patient with the necessary and adequate resources for the treatment. The reliability of this type of therapy allows the multiprofessional health care team to carry out various actions related to the provided care, confident in specific equipment functions, such as the audiovisual alarms that can be triggered in the event of a failure to comply with the patient-ventilator relationship. However, when the use of mechanical ventilator is shared, some of these functions may be lost and the health professional must be aware of the quality of the respiratory therapy that patients are receiving (Guery et al. 2013).

A single device was applied to two patients in the study described in Neyman and Irvin (2006). However, this approach presents weaknesses in the safe performance, such as the failure to perform PEEP control. Although the research in this area is inconclusive, the seriousness of the lack of mechanical ventilators in health care services caused by COVID19 has led to an emergency in the need to ventilate more than one patient with the same device.

Another criticism in the work presented by Neyman and Irvin (2006) was the use of identical test lungs, with similar compliance and tubes with the same resistance and diameter. However, this same methodology, when applied to patients with acute respiratory distress syndrome (ARDS), where pulmonary compliance can vary from 0.015 to $0.15 \mathrm{~L} / \mathrm{cmH} 2 \mathrm{O}$, the mechanical ventilator may not offer and cannot maintain the appropriate pressure and volume of medical gas to patients. Thus, even though pulmonary compliance is $25 \%$ in patients, differences in tidal volumes in volume or pressure ventilation modalities can occur (Branson 2006).

As demonstrated by Branson (2006), other factors that may influence the flow of medical gas delivered to patients should be considered, such as the following: variable amounts of secretion in the endotracheal tube and the airways, the level 
of sedation, presence of cough, dyspnea and, airway caliber. Other difficult points to control refer to the amount of oxygen received, the PEEP adjustment, and flow rate that cannot be adjusted individually, requiring more intense monitoring of these patients by the clinical staff.

The experiment carried out by Paladino et al. (2008b), used the same strategy as (Neyman and Irvin 2006), but with minor adaptations made in the patient circuit and adding the placement of a filter in the inspiratory branch. The experiment was conducted with four adult sheep in healthy conditions, which were placed on mechanical ventilation for $12 \mathrm{~h}$. The study showed that the hemodynamic conditions of the animals were maintained throughout the experiment. However, the animals had similar weights (in the range of $70 \mathrm{~kg}$ ) and did not present any type of comorbidity. The animals had undergone similar treatment conditions in the days before the experiment, meaning they did not present any type of characteristic that could influence the change in the hemodynamic data collected, as listed by Branson (2006).

Therefore, one of the relevant points to be observed regarding this sharing methodology would be the need for smart mechanical ventilators to predict the occurrence of changes that occur with the patient, in addition to the need to check the limitations of the double-lumen endobronchial tubes available on the market (Branson 2006; Cavanilles et al. 1979; Powner et al. 1977).

On March 26, 2020, the American Society of Anesthesiologists of the United States of America issued a note advising physicians not to use mechanical ventilator sharing (American Society of Anesthesiologists 2020b). According to the note, even with only a single patient per equipment, the mortality rate has remained between 40 and $60 \%$ due to the pathophysiological and therapeutic complexity of the acute respiratory syndrome in patients with COVID19. Among the reasons presented in this note, it can be mentioned that:

- Pulmonary volumes of patients whose pulmonary compliance is more preserved offer lung conditions that are more compatible with the programmed volumes and, therefore, would receive, as a priority, greater volumes of gas released by the equipment, and this could cause a deficit in this supply for another patient;

- Impossibility to control PEEP;

- Inability to monitor alarms: like in the event of cardiac arrest and, if the ventilation of a patient connected to the same equipment is stopped;

- Risk of contamination, even with identical clinical characteristics at the beginning of ventilation;

- Ethical issues, as the ventilator could save the life of a single person, and in this case, there is a risk of failure putting at risk the lives of all patients who are making shared use of the equipment.
The Food and Drug Administration (FDA) recently approved, in an emergency, the use of a Y-connector, using 3D printing technology, so that it can be used in the inspiratory and expiratory branches of the mechanical ventilator, as a way of divide the airflow for patient ventilation. In this way, a single machine could be used for up to four patients. However, the manufacturer emphasizes the importance of the patients' clinical characteristics being matched, since the machine will provide the same configuration conditions, such as oxygen concentration, amount of air in each breathing cycle and air pressure (Prisma Health 2020), considering the simulation models in the laboratory and disregarding the studies carried out by American Society of Anesthesiologists (2020b) and Branson (2006) on lung volume, PEEP control, and alarms.

It should be noted that studies conducted in the laboratory using test lungs or even healthy animals have produced positive results for the shared use of ventilators. However, as warned by the American Society of Anesthesiologists (USA), as well as by the American Association for Respiratory Care (USA), in real conditions (American Association for Respiratory Care 2020), the specific condition of patients such as weight, height, types of comorbidities, types of pathologies, and recovery time, among other factors, can prevent a real improvement in the patient's condition, promoting the spread of the virus and compromising the quality of care.

\section{Low cost or fast manufactured ventilator}

Another alternative, widely discussed by several countries, is the development of a low-cost mechanical ventilator that can meet the care needs, specifically, of patients affected by severe clinical manifestations of COVID-19. In this way, the search for technical and clinically acceptable characteristics for the development of this technology has been sought.

In this sense, the American regulation ASTM F920-93 (1999), which has the standard specification for minimum performance and safety requirements for small portable mechanical ventilators to be used in emergencies outside or inside hospital environments, can be used as a basis. The main characteristics of this standard defined by ASTM F920-93 are briefly listed in Table 2 . This summary was made by Shahid (2019) who developed a prototype of equipment whose production cost was below US\$500.

Table 2 presents the characteristics of another prototype developed based on a bag of Artificial Manual Breathing Unit (AMBUß) where it is possible to adjust the control of air volume, breaths per minute, and PEEP, for example. This system also has two ventilation modes that involve mandatory ventilation and assisted ventilation. According to Shahid (2019), the cost of production is less than US\$ 80.

The Massachusetts Institute of Technology (MIT) has a study on a low-cost ventilation system, also based on the use 
Table 2 Device functional requirements. Source: ASTM F920-93 (Husseini et al. 2010); AMBUß bag prototyping (Shahid 2019)

\begin{tabular}{|c|c|c|}
\hline Characteristics & ASTM F920-93 & Artificial Manual Breathing Unit (AMBUß) (Shahid 2019) \\
\hline Medical & $\begin{array}{l}\text { - User-specified breath/min insp./exp. ratio, tidal vol- } \\
\text { ume } \\
\text { - Assist control } \\
\text { - Positive end-expiratory pressure (PEEP) } \\
\text { - Maximum pressure limiting } \\
\text { - Humidity exchange } \\
\text { - Infection control } \\
\text { - Limited dead-space }\end{array}$ & $\begin{array}{l}\text { - Adjustable BPM } \\
\text { - Two basic modes were inclusive of mandatory and assist control ventilation. } \\
\text { - Adjustable inspiration to expiration rate } \\
\text { - Adjustable volume flow rate and pressure }\end{array}$ \\
\hline Mechanical & $\begin{array}{l}\text { - Portable } \\
\text { - Standalone operation } \\
\text { - Robust mechanical, electrical, and software systems } \\
\text { - Readily sourced and repairable parts } \\
\text { - Minimal power requirement } \\
\text { - Battery-powered }\end{array}$ & $\begin{array}{l}\text { - Portable in size } \\
\text { - Easily available sensors } \\
\text { - Power-efficient }\end{array}$ \\
\hline Economic & - Low-cost $(<\mathrm{US} \$ 500)$ & - Prototype cost $(<$ US\$ 80) \\
\hline User interface & $\begin{array}{l}\text { - Alarms for loss of power, loss of breathing circuit } \\
\text { integrity, high airway pressure, and low battery life } \\
\text { - Display of settings and status } \\
\text { - Standard connection ports }\end{array}$ & $\begin{array}{l}\text { - The micro-controller then displays by the flow sensor and pressure sensor } \\
\text { parameters on the mobile screen where if the needed physician could modify } \\
\text { them. }\end{array}$ \\
\hline Repeatability & $\begin{array}{l}\text { - Indicators within } 10 \% \text { of the correct reading } \\
\text { - Breath frequency accurate to one breath per minute }\end{array}$ & - Breath per minute rate adjustment \\
\hline
\end{tabular}

of AMBU® bags, which are already found in large quantities in hospitals. These bags are used for manual ventilation of the patient and are normally used when the patient enters a cardiac arrest while waiting for the availability of a mechanical ventilator. The developed system consists of a mechanical system that presses the AMBU® bag, releasing air to the patient. However, it must present a control of the pressure supplied, as well as the amount of air sent to the patient (Chandler 2020; Husseini et al. 2010).

The Regulatory Agency for Products in Medicine and Health Care (MHRA) of the United Kingdom (UK) has defined a series of points that a mechanical ventilator of fast manufacture must attend in an emergency, as is the case of COVID-19. The document presents an assessment of the existing regulations in its health legislation, to define those that could be safely relaxed (Shahid 2019). Thus, the main UK regulations necessary for the development of this fast manufacturing equipment are shown in Table 3, as shown in Medicines and Healthcare products Regulatory Agency (2020).

The MHRA further establishes that a ventilator with simpler specifications than the one presented in its report may not promote any clinical benefit, or even promote an increase in the possibility of leading to an increase in damage to the patient. It is important to remember that ventilation alone will not restore the patient's life because depending on the type of ventilatory assistance received, it can simply prolong the suffering without promoting any effect on his recovery. In this sense, MHRA presents in its specifications characteristics regarding the type of ventilation; gas and electricity; infection control; monitoring and alarms; biological security; and, software security. Test standards are also presented that must be performed to ensure the effectiveness of the equipment to be developed, such as safety standards according to ISO 80601-2-12: 2020 and usability tests according to ISO 62366 (Medicines and Healthcare products Regulatory Agency 2020).

In Brazil, there are several initiatives regarding the development of low-cost ventilators, such as the following: Breath4Life, in Florianópolis, SC; Frank 5010, in Caxias do Sul, RS; INSPIRE Poli/USP, in São Paulo, SP; INVENT IV01, in Niterói, RJ; RespNUTES NUTES/UEPB in Campina Grande, PB; VExCo COPPE/UFRJ in Rio de Janeiro, RJ; among others. Some of this equipment is under development and others are awaiting the evaluation and testing process for possible approval of the project by the health agencies and consequent production and distribution. This equipment can be based on an AMBUß bag, such as INSPIRE, or it will have the base of a simplified conventional mechanical ventilator. However, there are still no studies demonstrating the efficiency of this equipment, as well as an analysis of its technical specifications presented, such as Frank5010 and INVENT IV01 , given its use as a respiratory therapy for patients with COVID-19.

\section{High-flow nasal cannula}

A different form of oxygen support is being used and tested to prevent adverse events and health problems for patients, which are the high flow of the nasal cannula and this device can provide up to $100 \%$ oxygen. This treatment is indicated as a way to prevent intubation in patients who have respiratory 
Table 3 The MHRA UK most relevant standards for mechanical ventilator. Source: Medicines and Healthcare products Regulatory Agency (2020)

\begin{tabular}{ll}
\hline Standards-mechanical ventilator & Use and description \\
\hline BS EN 794-3:1998+A2:2009 & $\begin{array}{l}\text { Particular requirements for emergency and transport ventilators } \\
\text { ISO 10651-3:1997 }\end{array}$ \\
BS ISO 80601-2-84:2018 & $\begin{array}{c}\text { Medical electrical equipment. Part 2 to 84; particular requirements for basic safety and essential performance } \\
\text { of emergency and transport ventilators - especially the parts on 'patient gas pathway' safety } \\
\text { Medical electrical equipment - part 2-12: particular requirements for basic safety and essential performance } \\
\text { of critical care ventilators } \\
\text { ISO 80601-2-12:2020 }\end{array}$ \\
BS ISO 19223:2019 & ung ventilators and related equipment; vocabulary and semantics \\
\hline
\end{tabular}

arrest with acute hypoxemia (Arabi et al. 2020a). Adequate tissue oxygenation must be maintained in patients with acute respiratory failure, for whom oxygen supplementation is essential. The nasal cannula has several beneficial effects for patients with acute respiratory failure in intensive care units (ICU) and in emergency departments (Kang et al. 2015).

The high-flow nasal cannula has been indicated for patients with COVID-19 (Singhal 2020) as a way of preventing the intubation of patients who have respiratory arrest with acute hypoxemia (Arabi et al. 2020b). If the patient's condition worsens, the high-flow nasal cannula should be considered, starting at $20 \mathrm{~L} / \mathrm{min}$ and gradually increasing to $50-60 \mathrm{~L} / \mathrm{min}$. The oxygen fraction must be adjusted according to the oxygen saturation (Guo et al. 2020). There is no mention of any limitation in the use of the high-flow nasal cannula in the treatment of COVID-19 (Singhal 2020).

HFNC has several advantages over conventional oxygen therapy. However, compared to non-invasive mechanical ventilation, HFNC is unable to provide a gas flow rate or positive airway pressure as great as that of non-invasive mechanical ventilation. Therefore, the question arises about the applicability of HFNC compared to conventional oxygenation therapy and non-invasive mechanical ventilation. (Zhao et al. 2017) conducted a systematic review with meta-analysis, comparing HFNC with conventional oxygenation therapy and noninvasive mechanical ventilation, in relation to intubation rates, mechanical ventilation, increased respiratory support and mortality. The result of this systematic review showed that HFNC has a mortality rate equal to that of conventional oxygenation therapy, but reduces all other rates. There was no difference between HFNC and mechanical ventilation at any of the rates assessed. But it is important to note that HFNC as a respiratory support technique cannot delay the patient's intubation process. If this occurs for more than $48 \mathrm{~h}$, it could worsen the patient's clinical condition (Kang et al. 2015).

\section{Anesthesia machine as a mechanical ventilator}

Other forms of ventilatory systems are reported by the FDA in an open letter to health centers that, if necessary, the use of other ventilation mechanisms capable of providing controlled ventilation or assisted ventilation could be considered to cover the shortage of mechanical ventilators in these units. Among these options are the long-term use of transport ventilators and also the use of anesthesia machines (Food and Drug Administration 2020b).

For the implementation of safety techniques, in the use of anesthesia equipment as a mechanical ventilator, the American Association of Anesthesiologists (ASA) and the Patient Safety Foundation for Anesthesia (APSF), both from the United States of America, defined a series of guidelines and recommendations. Thus, it is recommended to use a highquality viral filter between the patient's respiratory circuit and airways. A second filter is recommended at the end of the expiratory branch in connection with the anesthesia machine. This procedure aims to protect the machine from contamination, which could be transmitted to subsequent patients. Also, the placement of the heat and humidity exchange filter (HMFE) preserves the humidity of the patient's airways. Another recommendation is the presence of anesthesia professionals who must always be involved in modifying and managing the use of this equipment (American Society of Anesthesiologists 2020a; Anesthesia Patient Safety Foundation 2020).

The preference for use is given to the use of ventilators of newer anesthesia equipment, as they have tidal volume compliance compensation deliveries, unaffected by the flow of fresh gas, as these can enable a more consistent tidal volume and more monitoring need. Several anesthesia machines manufacturers have configuration changes to optimize the use of these types of equipment (American Society of Anesthesiologists 2020a; Anesthesia Patient Safety Foundation 2020).

Several manufacturers recommend caution when using anesthesia machines as a mechanical ventilator, as these devices are not designed for continuous ventilation for several days, but at most for a few hours of use in surgery. Thus, it is necessary to assess the risks and benefits of performing this practice (Anesthesia Patient Safety Foundation 2020; Mindray 2020).

Some functional differences between anesthesia machines and mechanical ventilators must be evaluated. For example, the anesthesia system uses mandatory ventilation in patients 
with sedation and muscle relaxation, while mechanical ventilators can be used in sedated patients with neuromuscular blockers (e.g., ARDS) as well as in conscious patients breathing spontaneously (e.g., ventilatory weaning). In this sense, one must pay attention to the ventilation mechanisms of each anesthesia equipment to control the pressure limit in the airways and PEEP (Mindray 2020). Features such as air rebreathing, widely used in anesthesia, where there is a $\mathrm{CO} 2$ absorption system, will not be used in continuous ventilation, which has an open ventilation circuit. Another point of the analysis is the adjustment of $\mathrm{O} 2$ concentration, which in the anesthesia equipment is carried out with adjustable flows of fresh gas, while in the ventilator, this occurs through an $\mathrm{O} 2$ and airflow meter. Another interesting point is that anesthesia equipment does not support non-invasive ventilation, as if a leak occurred, the bellows could collapse. Anesthesia equipment also does not support specific functions for intensive care, such as inhalation retention, exhalation retention, lowflow pressure-volume loop, among other resources (Mindray 2020).

Therefore, the use of anesthesia equipment as a mechanical ventilator must always be performed by professionals who already know the technology. The equipment must always be evaluated before use, making sure that the adaptations to the required prolonged use are all satisfied. Its use must be analyzed with the needs of patients, and its effective efficiency must be analyzed (American Society of Anesthesiologists 2020a; Anesthesia Patient Safety Foundation 2020; Mindray 2020)

\section{Non-invasive ventilation}

Non-invasive ventilation (NIV) is a form of ventilatory support besides traditional ventilation, which is invasive mechanical ventilation. In these two situations, artificial ventilation is achieved by applying positive pressure to the airways. In NIV, a mask is used between the ventilator and the patient (Carvalho et al. 2007). According to Medicines and Healthcare products Regulatory Agency (2020), noninvasive ventilation can occur in the following forms: Continuous Positive Airway Pressure (CPAP), which provides a constant steady pressure to keep the lungs expanded; and, Bilevel Positive Airway Pressure (BIPAP), which provides different levels of pressure when the patient inhales and exhales.

CPAP is regularly used in spontaneously breathing patients who demand short-term mechanical assistance. BIPAP allows the adjustment of two different pressures during the inspiratory and expiratory phases of breath. It is generally used in patients with spontaneous breathing who require short-term mechanical assistance. In CPAP and BIPAP, the effectiveness of the therapy is intimately related to the proper sealing of the nasal or oral-nasal mask to the patient's face. Both devices can liberate air or a mixture of air and oxygen at high flow rates. CPAP allows to set an individual pressure, through a circuit and patient interface and BIPAP the higher inspiratory pressure reduces the patient's breathing effort, while the lower pressure helps to preserve an adequate alveolar volume and to prevent the collapse of unstable alveolar units during expiration (Barbas et al. 2014).

The National Library of Medicine (2020b) includes NIV as an item of the scale of respiratory therapy techniques to the hospitalized patient. In non-invasive ventilation procedures where aerosol generation occurs, healthcare professionals must wear respirators (e.g., N95, FFP2), eye protection, gloves, and aprons. Aprons should also be fluid resistant. These items are important to reduce the risk of contagion of health professionals (World Health Organization (WHO) 2020b).

In the study carried out by Singhal (2020) at a hospital in Wuhan, $76 \%$ of patients admitted with COVID-19, $13 \%$ received oxygen support by NIV and 4\% support with conventional mechanical ventilation. The average length of stay with NIV was 9 days and with invasive mechanical ventilation 17 days.

\section{Dilemma}

The health and economic dilemma arise in several countries at the moment when their regulations are being eased, to facilitate the registration of new technologies, to alleviate the impact linked to the growing demands of care for patients affected by COVID-19. It is possible to facilitate the authorization and compulsory registration of new technologies that may be developed in this period and linked to the care of this pandemic, enabling a more efficient manufacturing and distribution process (BRASIL 2020; Food and Drug Administration 2020a; Medicines and Healthcare products Regulatory Agency 2020).

At ethical bias in health, another dilemma has been identified that arises from the fact that, at the height of the epidemic by COVID-19, there is a lack of equipment for all patients with severe clinical conditions. In recent statements by local authorities in one of the cities most affected by the spread of COVID-19 in the USA, New York, it was reported that regarding the length of stay in Intensive Care Units in that city, patients without the SARS-CoV-2 virus remain on mechanical ventilation, usually for 3 or 4 days. However, patients with SARS-CoV-2 have been kept connected to mechanical ventilators for 11 to 21 days (Benjamim 2020).

So, what would be the best decision regarding the need to keep the patient connected or not to mechanical ventilation? To assist in this process, in Hick et al. (2007), a matrix assessment with decision criteria was presented. Among the presented criteria, there is the SOFA protocol (Sequential Organ Failure Assessment). This matrix evaluation covers a wide 
variety of pathologies, where few laboratory variables are used and without invasive hemodynamic variables. This protocol is not validated for pediatric use. The SOFA result provides a patient prognosis and a number that can be compared across institutions, helping to allocate regional resources. However, caution should be exercised when using it in a pandemic, since the average scores are low among patients.

As presented by Berlinger et al. (2020), the act of acting ethically is part of professionalism in the health area. However, health professionals experience anxieties and uncertainties when faced with these complex contexts brought to the fore, amid the exhaustive routine of their professional activities in health care. Thus, in situations of public emergency, screening protocols help first responders to quickly prioritize patients for different levels of care. Faced with a catastrophe or disaster scenario, determining which patients will be able to receive mechanical ventilation assistance is a difficult process, both from a clinical and psychological point of view (Hick et al. 2007).

\section{Conclusion}

An important point presented in this paper is the importance of training professionals who use each one of the presented technologies. Operational knowledge makes it easier to handle the applied technique, and this information provides the action and care protocols that are defined for the safe handling of technologies. The use of ECMO and anesthesia machines are examples of the need for this training to provide complex therapeutic interventions with stringent infection control measures.

This study also presented techniques that can be used in the routine of health services as oxygenation support techniques, in critical situations, such as those caused by pandemics, like as COVID-19. Among these techniques, the described in this study were the following: (I) ECMO; (II) sharing mechanical ventilator; (III) fast production technologies, with low cost; (IV) high-flow nasal cannula; (V) anesthesia machine as mechanical ventilators; and, (VI) non-invasive ventilation.

The need for ECMO is still relatively low, and its use is restricted to specialized centers worldwide. ECMO requires careful planning with careful resource allocation and staff training to provide complex therapeutic interventions, with rigorous infection control measures, which are crucial elements in an ECMO action plan.

The proposed solution of sharing the same mechanical respirator with two to four patients, despite present positive results in tests with a simulator, does not yet have a study in clinical practice that shows its efficiency in maintaining adequate respiratory parameters for the treatment of the patient. There are also no studies that demonstrate the efficiency in preventing cross-contamination among patients during mechanical ventilator. About the respirators of simple construction and low cost are based on bags of AMBU® and these may not offer the necessary clinical benefits for patient care, as no clinical studies are demonstrating their efficiency against COVID-19.

Despite its indication to avoid intubation in a patient with ARDS using the high-flow nasal cannula, it is still not possible to say whether there is a limitation in the use of this equipment in the treatment of COVID-19. Regarding the anesthesia machine, it is recommended to use a high-quality filter, both to avoid contamination of patients and equipment. In respect to NIV, studies indicated the possibility of a shorter hospitalization time when compared to traditional mechanical ventilation.

Therefore, despite the various alternatives presented and used as oxygenation support for patients with COVID-19, there is a need to elaborate solutions to supply the shortage of conventional mechanical fans worldwide specially in a critical period of a global pandemic.

Funding The authors would like to thank the National Council for Scientific and Technological Development (CNPq), Coordination of Improvement of Higher-Level Personnel (CAPES Program CAPES/ DFATD-88887.159028/2017-00, Program CAPES/COFECUB88881.370894/2019-01), and Foundation for Research Support of the State of Minas Gerais (FAPEMIG-APQ-00942-17). A. O. Andrade and A. A. Pereira are fellows of CNPq, Brazil (304818/2018-6 and 310911/ 2017-6, respectively).

\section{Compliance with ethical standards}

Conflict of interest The authors declare that they have no conflict of interest.

\section{References}

Alhazzani W, Møller MH, Arabi YM, Loeb M, Gong MN, Fan E, et al. Surviving Sepsis Campaign: guidelines on the management of critically ill adults with Coronavirus Disease 2019 (COVID-19). Intensive Care Med. 2020;46:854-87. https://doi.org/10.1007/ s00134-020-06022-5.

American Association for Respiratory Care. Joint Statement on Multiple Patients Per Ventilator. AARC. 2020. [cited 2020 April 2]. Available from: https://www.aarc.org/joint-statement-guidancedocument-on-multiple-patients-per-ventilator/.

American Society of Anesthesiologists. Guidance on Purposing Anesthesia Machines as ICU Ventilators. ASA. 2020a. [cited 2020 April 4]. Available from: https://www.asahq.org/in-the-spotlight/ coronavirus-covid-19-information/purposing-anesthesia-machinesfor-ventilators.

American Society of Anesthesiologists. Joint Statement on Multiple Patients Per Ventilator. ASA. 2020b. [cited 2020 March 28]. Available from: https://www.asahq.org/about-asa/newsroom/newsreleases/2020/03/joint-statement-on-multiple-patients-perventilator.

Anesthesia Patient Safety Foundation. Faq On Anesthesia Machine Use, Protection, And Decontamination During The Covid-19 Pandemic. APSF. 2020. [cited 2020 April 4]. Available from: https://www. 
apsf.org/faq-on-anesthesia-machine-use-protection-anddecontamination-during-the-covid-19-pandemic/.

Arabi YM, Al-Omari A, Mandourah Y, Al-Hameed F, Sindi AA, Alraddadi B, et al. Critically ill patients with the Middle East respiratory syndrome. Crit Care Med. 2017;45:1683-95. https://doi.org/ 10.1097/CCM.0000000000002621.

Arabi YM, Fowler R, Hayden FG. Critical care management of adults with community-acquired severe respiratory viral infection. Intensive Care Med. 2020a;46:315-28. https://doi.org/10.1007/ s00134-020-05943-5.

Arabi YM, Fowler R, Hayden FG. Critical care management of adults with community-acquired severe respiratory viral infection. Intensive Care Med. 2020b;46:315-28. https://doi.org/10.1007/ s00134-020-05943-5.

Barbas CSV, Ísola AM, Farias AM de C, Cavalcanti AB, Gama AMC, ACM D, et al. Brazilian recommendations of mechanical ventilation 2013. Part I. Rev Bras Ter Intensiva. 2014:26. https://doi.org/10. 5935/0103-507X.20140017.

Benjamim S. New York approves ventilator splitting, allowing hospitals to treat two patients with one machine. ABC News. 2020. [cited 2020 March 30]. Available from: https://abcnews.go.com/US/ york-approves-ventilator-splitting-allowing-hospitals-treat-patients/ story $? \mathrm{id}=69816167 \&$ cid=clicksource 43806452 takeover 2 headlines hed\&fbclid=IwAR2EqCXLo5zZN 5 TSJXZzcN $\bar{p}$ B5ytErStWN6HPTd8AkvTL3xtPqKQZ1vWSY54.

Berlinger N, Wynia M, Powell T, Hester DM, Milliken A, Fabi R, Cohn F, Guidry-Grimes LK, Watson JC, Bruce L, Chuang EJ, Oei G, Abbott J, Jenks NP. Ethical Framework for Health Care Institutions Responding to Novel Coronavirus SARS-CoV-2 (COVID-19) Guidelines for Institutional Ethics Services responding to COVID-19 managing uncertainty, safeguarding communities, guiding practice. Hast Cent. 2020. [cited 2020 April 4]. Available from: https://www.thehastingscenter.org/wp-content/uploads/ HastingsCenterCovidFramework2020.pdf.

Branson RD. A single ventilator for multiple simulated patients to meet disaster surge. Acad Emerg Med. 2006;13:1352-3. https://doi.org/ 10.1197/j.aem.2006.10.002

BRASIL. RDC 349:2020 - Dispõe sobre os critérios e os procedimentos extraordinários e temporários para tratamento de petições de regularização de equipamentos e de outros dispositivos médicos decorrente do novo Coronavírus. Ministério Da Saúde Agência Nac Vigilância Sanitária ANVISA. 2020. [cited 2020 April 2]. Available from: http://portal.anvisa.gov.br/documents/10181/ 5809525/RDC 3492020 .pdf/1db02b46-604a-4345-8362$8267 \mathrm{bb} 802045$.

Cavanilles J, Garrigosa F, Prieto C, Oncins J. A selective ventilation distribution circuit (S.V.D.C). Intensive Care Med. 1979;5:95-8.

Chandler DL. MIT-based team works on rapid deployment of opensource, low-cost ventilator. Massachusetts Inst Technol. 2020. [cited 2020 March 28]. Available from: http://news.mit.edu/2020/ ventilator-covid-deployment-open-source-low-cost-0326.

Chinese Medical Association. Novel Coronavirus Pneumonia Emergency Response Epidemiology Team. The epidemiological characteristics of an outbreak of 2019 novel coronavirus diseases (COVID-19). Chinese J Epidemiol. 2020;41:145-51. https://doi. org/10.3760/cma.j.issn.0254-6450.2020.02.003.

Chu DK, Kim LH-Y, Young PJ, Zamiri N, Almenawer SA, Jaeschke R, et al. Mortality and morbidity in acutely ill adults treated with liberal versus conservative oxygen therapy (IOTA): a systematic review and meta-analysis. Lancet. 2018;391:1693-705. https://doi.org/10. 1016/S0140-6736(18)30479-3.

Colafranceschi AS, Matos LN, Alves H, Meier MA. Oxigenação por membrana extra-corporea (ECMO). Acad Nac Med. 2020. [cited 2020 March 28]. Available from: http://webcache. googleusercontent.com/search?q=cache:32SIMKAoiVkJ:www. anm.org.br/conteudo_view.asp\%3Fid\%3D2420\%26descricao\%
3DOXIGENA \%25C3\%2587\%25C3\%25830\%2BPOR\% 2BMEMBRANA\%2BEXTRA-CORP\%25C3\%2593REA\% $2 \mathrm{~B}(\mathrm{ECMO})+\& \mathrm{~cd}=2 \& \mathrm{hl}=\mathrm{pt}-\mathrm{BR} \& \mathrm{ct}=\mathrm{clnk} \& \mathrm{gl}=\mathrm{br}$.

Combes A, Hajage D, Capellier G, Demoule A, Lavoué S, Guervilly C, et al. Extracorporeal membrane oxygenation for severe acute respiratory distress syndrome. N Engl J Med. 2018;378:1965-75. https:// doi.org/10.1056/NEJMoa1800385.

da Silva AAM. Sobre a possibilidade de interrupção da epidemia pelo coronavírus (COVID-19) com base nas melhores evidências científicas disponíveis. Rev Bras Epidemiol. 2020;23. https://doi. org/10.1590/1980-549720200021.

Darwood A, McCanny J, Kwasnicki R, Martin B, Jones P. The design and evaluation of a novel low-cost portable ventilator. Anaesthesia. 2019;74:1406-15. https://doi.org/10.1111/anae.14726.

de Carvalho CRR, Toufen Junior C, Franca SA. Ventilação mecânica: princípios, análise gráfica e modalidades ventilatórias. J Bras Pneumol. 2007;33:54-70. https://doi.org/10.1590/S180637132007000800002.

Ducharme J. World Health Organization declares COVID-19 a "pandemic." Here's what that means. Time Mag. 2020. [cited 2020 March 28]. Available from: https://time.com/5791661/whocoronavirus-pandemic-declaration/.

Extracorporeal Life Support Organization. Recomendações ELSO: ECMO para pacientes com COVID-19 com insuficiência cardíaca e/ou pulmonar grave. ELSO. 2020a. [cited 2020 March 31]. Available from: www.elso.org/Portals/0/Files/Guideline/ELSO COVID-19 Guidance Document.Portugeuse (1).pdf.

Extracorporeal Life Support Organization. Webinar: Aerossolização pela membrana de ECMO em pacientes com COVID-19. ELSO. $2020 \mathrm{~b}$. [cited 2020 April 5]. Available from: https://www.elso.org/ COVID19/ECMOInCOVID19.aspx.

Food and Drug Administration. Coronavirus (COVID-19) Update: FDA continues to facilitate access to crucial medical products, including ventilators. FDA. 2020a. [cited 2020 April 2]. Available from: https://www.fda.gov/news-events/press-announcements/ coronavirus-covid-19-update-fda-continues-facilitate-accesscrucial-medical-products-including.

Food and Drug Administration. Ventilator supply mitigation strategies: letter to health care providers. FDA. 2020b. [cited 2020 April 4]. Available from: https://www.fda.gov/medical-devices/lettershealth-care-providers/ventilator-supply-mitigation-strategies-letterhealth-care-providers.

Guery B, Poissy J, el Mansouf L, Séjourné C, Ettahar N, Lemaire X, et al. Clinical features and viral diagnosis of two cases of infection with Middle East respiratory syndrome coronavirus: a report of nosocomial transmission. Lancet. 2013;381:2265-72. https://doi.org/10. 1016/S0140-6736(13)60982-4.

Guo YR, Cao QD, Hong ZS, Tan YY, Chen SD, Jin HJ, et al. The origin, transmission and clinical therapies on coronavirus disease 2019 (COVID-19) outbreak-an update on the status. Mil Med Res. 2020;7. https://doi.org/10.1186/s40779-020-00240-0.

Hick JL, Rubinson L, O'Laughlin DT, Farmer JC. Clinical review: Allocating ventilators during large-scale disasters-problems, planning, and process. Crit Care. 2007;11:217. https://doi.org/10.1186/ cc5929.

Higgins JP, Green S. Cochrane handbook for systematic reviews of interventions 4.2.6 [updated September 2006]. In: The Cochrane Library. 4th ed. Chichester, UK: John Wiley \& Sons, Ltd.; 2006.

Husseini AM Al, Lee HJ, Negrete J, Powelson S, Servi A, Slocum A, Saukkonen J. Design and prototyping of a low-cost portable mechanical ventilator. Proc. 2010 Des. Med. Devices Conf., Minneapolis, MN, USA; 2010.

Kang BJ, Koh Y, Lim CM, Huh JW, Baek S, Han M, et al. Failure of high-flow nasal cannula therapy may delay intubation and increase mortality. Intensive Care Med. 2015;41:623-32. https://doi.org/10. 1007/s00134-015-3693-5. 
Khandaker G, Dierig A, Rashid H, King C, Heron L, Booy R. Systematic review of clinical and epidemiological features of the pandemic influenza A (H1N1) 2009. Influenza Other Respir Viruses. 2011;5:148-56. https://doi.org/10.1111/j.1750-2659.2011.00199.x.

Levison ME. Comentários - COVID-19: o que sabemos sobre infecções pelo coronavírus humano. Man MSD Versão Para Profissionais Saúde Merck Co, Inc. 2020. [cited 2020 April 3]. Available from: https://www.msdmanuals.com/pt/profissional/news/editorial/2020/ 02/26/18/41/covid-19-what-we-know.

Medicines \& Healthcare products Regulatory Agency. Guidance Rapidly manufactured ventilator system specification. Dep Heal Soc Care MHRA-UK. 2020. [cited 2020 March 27]. Available from: https:// assets.publishing.service.gov.uk/government/uploads/system/ uploads/attachment_data/file/876167/RMVS001_v3.1.pdf.

Mindray. Mindray A-Series Anesthesia Delivery System Consideration for use as a Ventilator. Mindray North Am. 2020. [cited 2020 April 6]. Available from: https://www.mindraynorthamerica.com/wpcontent/uploads/2020/03/1658B-Considerations-for-MR-AnesSys-used-for-Ventilators-during-COVID-19-1.pdf.

Moher D, Shamseer L, Clarke M, Ghersi D, Liberati A, Petticrew M, et al. Preferred reporting items for systematic review and meta-analysis protocols (PRISMA-P) 2015 statement. Rev Esp Nutr Humana y Diet. 2016;20:148-60. https://doi.org/10.1186/2046-4053-4-1.

National Library of Medicine. Streptokinase versus unfractionated heparin nebulization in severe ARDS. Natl Inst Heal. 2018. [cited 2020 April 1]. Available from: https://clinicaltrials.gov/ct2/show/ NCT03465085.

National Library of Medicine. A randomized multicenter controlled clinical trial of arbidol in patients with 2019 novel coronavirus (2019nCoV). Natl Inst Heal. 2020a. [cited 2020 April 1]. Available from: https://doi.org/10.1002/central/CN-02054551/full.

National Library of Medicine. Adaptive COVID-19 treatment trial. Natl Inst Heal. 2020b. [cited 2020 April 1]. Available from: https:// clinicaltrials.gov/show/NCT04280705.

National Library of Medicine. Bevacizumab in severe or critical patients with COVID-19 pneumonia-RCT. Natl Inst Heal. 2020c. [cited 2020 April 1]. Available from: https://doi.org/10.1002/central/CN02088992/full.

National Library of Medicine. Mild/moderate 2019-nCoV remdesivir RCT. Natl Inst Heal. 2020d. [cited 2020 April 1]. Available from: https://clinicaltrials.gov/ct2/show/NCT04252664.

National Library of Medicine. Nitric oxide gas inhalation therapy for mild/moderate COVID19 infection. Natl Inst Heal. 2020e. [cited 2020 April 1]. Available from: https://clinicaltrials.gov/ct2/show/ NCT04290858.

National Library of Medicine. Vitamin C infusion for the treatment of severe 2019-nCoV infected pneumonia. Natl Inst Heal. 2020f. [cited 2020 April 1]. Available from: https://clinicaltrials.gov/show/ NCT04264533.

Neyman G, Irvin C. A single ventilator for multiple simulated patients to meet disaster surge. Acad Emerg Med. 2006;13:1246-9.

Paladino L, Silverberg M, Charchaflieh JG, Eason JK, Wright BJ, Palamidessi N, et al. Increasing ventilator surge capacity in disasters: ventilation of four adult-human-sized sheep on a single ventilator with a modified circuit. Resuscitation. 2008a;77:121-6. https://doi. org/10.1016/j.resuscitation.2007.10.016

Paladino L, Silverberg M, Charchaflieh JG, Eason JK, Wright BJ, Palamidessi N, et al. Increasing ventilator surge capacity in disasters: ventilation of four adult-human-sized sheep on a single ventilator with a modified circuit. Resuscitation. 2008b;77:121-6. https://doi. org/10.1016/j.resuscitation.2007.10.016

Pan American Health Organization. Folha informativa - COVID-19 (doença causada pelo novo coronavírus). OPAS Bras. 2020. [cited
2020 March 28]. Available from: https://www.paho.org/bra/index. php?option $=$ com content $\& v i e w=\operatorname{article} \& i d=6101$ : covid19\&Itemid $=875$.

Powner D, Eross B, Grenvik A. Differential lung ventilation with PEEP in the treatment of unilateral pneumonia. Crit Care Med. 1977;5: $170-2$.

Prisma Health. Prisma Health introduces VESper ${ }^{\mathrm{TM}}$. Prism Heal. 2020. [cited 2020 March 31]. Available from: https://www.prismahealth. org/vesper/.

Ramanathan K, Antognini D, Combes A, Paden M, Zakhary B, Ogino M, et al. Planning and provision of ECMO services for severe ARDS during the COVID-19 pandemic and other outbreaks of emerging infectious diseases. Lancet Respir Med. 2020;8:518-26. https://doi. org/10.1016/S2213-2600(20)30121-1.

Schmidt M, Hajage D, Lebreton G, Monsel A, Voiriot G, Levy D, et al. Extracorporeal membrane oxygenation for severe acute respiratory distress syndrome associated with COVID-19: a retrospective cohort study. Lancet Respir Med. 2020. https://doi.org/10.1016/ S2213-2600(20)30328-3.

Shahid M. Prototyping of artificial respiration machine using AMBU bag compression. 2019 Int. Conf. Electron. Information, Commun., IEEE; 2019, p. 1-6. https://doi.org/10.23919/ELINFOCOM.2019. 8706360.

Shenoy N, Luchtel R, Gulani P. Considerations for target oxygen saturation in COVID-19 patients: are we under-shooting? BMC Med. 2020;18:260. https://doi.org/10.1186/s12916-020-01735-2.

Singhal T. A review of coronavirus disease-2019 (COVID-19). Indian J Pediatr. 2020;87:281-6. https://doi.org/10.1007/s12098-02003263-6.

Tsouderos TK. COVID-19: Q\&A on SARS-CoV-2, how it compares to previous coronavirus outbreaks and how hard it will be to develop vaccines and drugs. HRI Regul Cent Lead. 2020. [cited 2020 April 3]. Available from: https://www.pwc.com/us/en/industries/healthindustries/library/qa-covid-19-compares-previous-coronavirusoutbreaks.html.

World Health Organization (WHO). Pandemic influenza preparedness and response: a WHO guidance document. WHO. 2009. Available from: https://apps.who.int/iris/bitstream/handle/10665/44123/ 9789241547680_eng.pdf.

World Health Organization (WHO). Report of the WHO-China Joint Mission on Coronavirus Disease 2019 (COVID-19). 2020a.

World Health Organization (WHO). Severe Acute Respiratory Infections Treatment Centre Practical manual to set up and manage a SARI treatment centre and a SARI screening facility in health care facilities. WHO. 2020b.

Wunsch H. Mechanical ventilation in COVID-19: interpreting the current epidemiology. Am J Respir Crit Care Med. 2020;202:1-4. https:// doi.org/10.1164/rccm.202004-1385ED.

Yang X, Yu Y, Xu J, Shu H, Xia J, Liu H, et al. Clinical course and outcomes of critically ill patients with SARS-CoV-2 pneumonia in Wuhan, China: a single-centered, retrospective, observational study. Lancet Respir Med. 2020;8:475-81. https://doi.org/10.1016/S22132600(20)30079-5.

Zhao H, Wang H, Sun F, Lyu S, An Y. High-flow nasal cannula oxygen therapy is superior to conventional oxygen therapy but not to noninvasive mechanical ventilation on intubation rate: a systematic review and meta-analysis. Crit Care. 2017;21:184. https://doi.org/10. 1186/s13054-017-1760-8

Publisher's note Springer Nature remains neutral with regard to jurisdictional claims in published maps and institutional affiliations. 